JURNAL SPORTA SAINTIKA

P-ISSN 2502-5651

E-ISSN 2579-5910

\title{
Hubungan Reaction Time dan Power Lengan dengan Kecepatan Bola Hasil Smash pada Permainan Tenis Meja
}

\author{
Januar Ramadhan ${ }^{1}$, Nurlan Kusmaedi ${ }^{2}$, Ahmad Hamidi ${ }^{3}$ \\ ${ }^{1}$ Universitas Pendidikan Indonesia, Pendidikan Jasmani Kesehatan dan \\ Rekreasi, Bandung,Indonesia \\ ${ }^{2}$ Universitas Pendidikan Indonesia, Pendidikan Jasmani Kesehatan dan \\ Rekreasi, Bandung,Indonesia \\ ${ }^{3}$ Universitas Pendidikan Indonesia, Pendidikan Jasmani Kesehatan dan \\ Rekreasi, Bandung,Indonesia
}

Januarramadhan1901@gmail.com, nurlankusmaedi11@gmail.com,

ahmadhamidi@upi.edu

\begin{abstract}
This research is motivated by the importance of physical components to the results of the speed of the smash on table tennis including reaction time and arm power. The purpose of this study was to determine the relationship between reaction time and arm power with the speed of a smash ball in a table tennis game. This study uses a correlational research method. The sample in this study were active members of the Jabung Garut club. A total of 20 samples were taken using purposive sampling technique. The instruments used in this study are the ruler drop test to measure the speed of reaction time and the softball throw test to measure arm power. Data analysis used Statistical Product for Social Science (SPSS) version 22. The results of data analysis showed that there was a significant relationship between reaction time and the smash ball speed, which was $p=0.000<0.05$ with a value of $r=-0.719$, while the relationship between arm power and ball speed smash results $p=0.001<0.05$ which means there is a significant relationship, and the relationship between reaction time and arm power together with the ball speed smash results produce a significant relationship with the significance of $0.001<0.05$ and $r=0.547$. From these results it can be concluded that there is a significant relationship between reaction time and arm power with the speed of the ball smash in table tennis.
\end{abstract}

Key words : Table Tennis, Smash Ball, Reaction Time, Arm Power

\section{Abstrak}

Penelitian ini dilatarbelakangi oleh pentingnya komponen fisik terhadap hasil kecepatan smash pada tenis meja diantaranya reaction time dan power lengan. Tujuan penelitian ini untuk mengetahui hubungan antara reaction time dan power lengan dengan kecepatan bola hasil smash pada permainan tenis meja. Penelitian ini menggunakan metode penelitian korelasional. Sampel pada 
JURNAL SPORTA SAINTIKA

P-ISSN 2502-5651

E-ISSN 2579-5910

penelitian ini adalah anggota aktif club PTM Jabung Garut. Sebanyak 20 orang sampel diambil dengan menggunakan teknik purposive sampling. Instrumen yang digunakan pada penelitian ini yaitu ruler drop test untuk mengukur kecepatan waktu reaksi dan tes softball throw untuk mengukur power lengan. Analisis data menggunakan Statistical Product for Social Science (SPSS) versi 22. Hasil analisis data menunjukan terdapat hubungan yang signifikan antara reaction time dengan kecepatan bola hasil smash yaitu $\mathrm{p}=0.000<0.05$ dengan nilai $r=-0.719$, sedangkan hubungan power lengan dengan kecepatan bola hasil smash $\mathrm{p}=0.001<0.05$ yang bermakna terdapat hubungan yang signifikan, dan hubungan reaction time dan power lengan secara bersama dengan kecepatan bola hasil smash menghasilkan hubungan yang signifikan dengan signifikanasi $0.001<0.05$ dan nilai $r=0.547$. Dari hasil tersebut dapat disimpulkan bahwa terdapat hubungan yang signifikan antara reaction time dan power lengan dengan kecepatan bola hasil smash pada permainan tenis meja.

Kata kunci : Tenis Meja, Smash, Reaction Time, Power Lengan

\section{PENDAHULUAN}

Dalam Olahraga tenis meja sangat digemari oleh berbagai kalangan, dari anak-anak sampai dewasa dengan partisipan yang luar biasa banyak, bisa kita lihat hampir di setiap tempat dari berbagai lapisan masyarakat, ini di perkuat oleh pendapat Larry Hodges (1996) yang menyatakan bahwa "Permainan tenis meja merupakan cabang olahraga raket yang popular di dunia dan jumlah pesertanya menempati urutan kedua". Tenis meja mulai dipertandingkan pada olimpiade seoul dan menjadi perhatian dunia. Hodges (1996).

Pada kenyataanya, olahraga tenis meja sering dianggap tidak banyak memerlukan kebutuhan fisik, dilihat dari peralatan yang cukup ringan, luas permainan yang kecil dan durasi bermain yang singkat Lees (2003). Namun pada hakikatnya atlet yang ingin mencapai prestasi tertinggi, kondisi fisiknya harus mempuni agar bisa bermain dengan baik djokic (2014) dan Komponen penting dalam mempersiapkan atlet untuk kinerja maksimal adalah dengan mengevaluasi kapasitas fisik mereka (Joyce \& Lewindon, n.d.). Melihat dari karakteristik permainan tenis meja yang menuntut untuk bermain cepat, dengan demikian pemain tenis meja dituntut untuk memiliki kemampuan refleks yang tinggi Djokic (2014), Maka permainan tenis meja dimasukan kedalam kategori olahraga reaksi Yoshida et al., (1995). Penelitian yang dilakukan oleh Mansec, Dorel, Hug \& Jubaeu (2017) bahwa pukulan offensive menghasilkan permintaan fisik yang lebih besar daripada pukulan deffensive. Untuk mendapatkan poin dari lawan, maka pemain perlu membuat lawannya merasa kesulitan dalam melakukan pengembalian karena tenis meja dimainkan di lapangan yang sangat kecil, 
JURNAL SPORTA SAINTIKA

P-ISSN 2502-5651

E-ISSN 2579-5910

bermain dengan jarak pendek selama melakukan rally, pemain harus mampu melakukan gerakan ledakan singkat dengan cepat dan sering mengubah arah untuk memukul bola secara efektif Pradas, de Teresa, \& Vargas (2005). Salah satu teknik penyerangan yang biasa digunakan yaitu smash. Smash adalah tembakan tercepat pada tenis meja dan hampir tidak mungkin untuk kembali, mencapai kecepatan sekitar 60 mph sampai lebih dari 100 mph USATT (2004).

Reaction Time adalah indikator akurat kecepatan dan efektifitas pengambilan keputusan. Waktu reaksi (RT) adalah waktu yang telah berlalu antara presentasi stimulus sensorik dan respons perilaku berikutnya. Ini didefinisikan sebagai interval antara presentasi dari stimulus yang tidak terduga dan awal respon Schmidt \& Wrisburg (2004). Sementara itu power adalah produk dari kekuatan dan kecepatan, kemampuan otot untuk mengarahkan kekuatan maksimal dalam waktu yang amat singkat.

\section{METODELOGI PENELITIAN}

Penelitian ini merupakan penelitian korelasi, yaitu hubungan antara dua variabel atau lebih tanpa adanya upaya untuk mencari sebab akibat Fraenkel, Wallen, \& Hyun (2013), dimana tujuannya adalah untuk mengetahui bagaimana hubungan reaction time dan power lengan dengan kecepatan bola hasil smash pada permainan tenis meja.

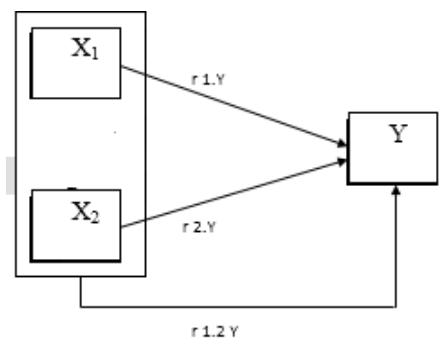

Gambar 1 Desain Penelitian Sumber: Sugiyono (2012)

Partisipan yang terlibat dalam penelitian ini adalah berjumlah 20 orang yang merupakan atlet pada PTM Jabung Garut. Penelitian ini dilakukan di PTM Jabung Garut. Populasi pada penelitian ini adalah atlet tenis meja di PTM Jabung Garut sebanyak 35 orang. Adapun karakteristiknya yaitu merupakan anggota klub, menguasai teknik permainan tenis meja, memiliki kemampuan smash diatas rata-rata. Kemudian dilakukan teknik purposive sampling, sehingga jumlah sampel yang digunakan yaitu sebanyak 20 orang.

Dalam penelitian ini digunakan beberapa intrumen untuk mendapatkan 
JURNAL SPORTA SAINTIKA

P-ISSN 2502-5651

E-ISSN 2579-5910

data, yaitu:

\section{Tes Ruler Drop}

Ruler Drop Test ini menggunakan sifat-sifat gravitasi yang diketahui untuk menentukan berapa lama seseorang untuk merespons jatuhan suatu benda dengan mengukur pada jarak berapa $(\mathrm{cm})$ itu ditangkap.Tujuannya adalah untuk mengukur waktu reaksi. Perlengkapan yang dibutuhkan yaitu Penggaris $30 \mathrm{~cm}$. Adapun pelaksanaan tes sebagai berikut :

1) Penggaris dipegang oleh asisten antara jari telunjuk dan ibu jari tangan dominan atlet yang terentang sehingga bagian atas ibu jari atlet sejajar dengan garis nol sentimeter pada penggaris.

2) Asisten menginstruksikan atlet untuk menangkap penggaris sesegera mungkin setelah penggaris dilepaskan.

3) Asisten melepaskan penggaris dan atlet menangkap penggaris diantara jari telunjuk dan ibu jari mereka secepat mungkin.

4) Asisten mencatat jarak antara bagian bawah dan bagian atas ibu jari atlet yang berhasil menangkap penggaris.

5) Tes ini dilakukan 2 kali percobaan dan nilai terbaik yang diambil sebagai hasil akhir.

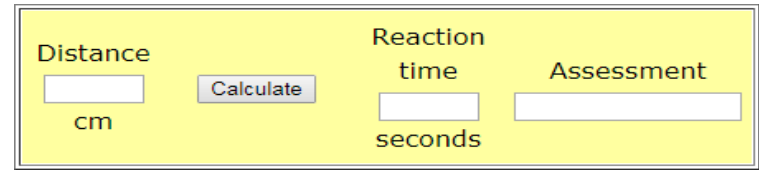

Gambar 2. Kalkulator Online Reaction Time

(sumber: Mackenzie, B. (2004)

2. Tes power lengan dengan Softball Throw Tujuan tes ini untuk mengukur power lengan.

Perlengkapan yang digunakan yaitu Bola Softball, Meteran, Alat tulis, Adapun pelaksanaan tes sebagai berikut:

1) Atlet berdiri dibelakang garis yang telah ditandai sebagai tanda garis awal

2) Atlet tidak diperkenankan melewati garis penanda saat melakukan lemparan, apabila terjadi maka tidak dihitung atau diulang

3) Menggunakan lengan yang dominan

4) Apabila bola terlempar keluar dari zona lemparan maka dianggap 
JURNAL SPORTA SAINTIKA

P-ISSN 2502-5651

E-ISSN 2579-5910

gagal

5) Atlet diperkenankan melakukan 2 kali percobaan

6) Hasil lemparan di hitung mulai dari garis penanda sampai dengan pertama kali bola mendarat, diambil hasil terbaik dari 2 kali percobaan. Sumber: Wood, R. J. (2010)

3. Tes kecepatan smash, dengan Software Kinovea

Tujuan tes ini adalah untuk mengukur kecepatan bola. Peralatan yang diperlukan yaitu meja tenis meja, 10 bola tenis meja, 1 buah kamera full hd,dan laptop. Adapun pelaksanaan tes sebagai berikut:

1) Pemain bersiap dilapangan permainan.

2) Kamera dalam keadaan siap dan pada kondisi slow motion agar pada saat di analisis menggunakan kinovea, bola bisa terdeteksi dengan baik.

3) Bola dilambungkan ke arah pemain.

4) Pemain melakukan pukulan smash yang dilakukan dengan maksimal.

5) Hasil rekaman video dari kamera dianalisis menggunakan kinovea untuk mengetahui kecepatan bola. Dilakukan penyesuaian kecepatan video yaitu dengan mengembalikannya pada keadaan $120 \mathrm{fps}$. selanjutnya dilakukan kalibrasi jarak agar perhitungan ukuran sesuai dengan keadaan asli. Kecepatan bola mulai dihitung dari saat bola mengenai bet sampai dengan menyentuh permukaan meja.

6) Tes dilakukan 10 kali dan diambil rata-rata.

Dalam penelitian,ini analisis data di olah dengan menggunakan metode kuantitatif dan dapat diselesaikan dengan analisis statistika. Analisis statistik ini menggunakan aplikasi komputer bernama Statistical Package Social Science (SPSS) versi 22. Dilakukan beberapa tahap uji yaitu uji normalitas menggunakan shapiro wilk dan uji hipotesis analisis data menggunakan analisis uji Correlate Bivariate untuk menguji antara satu variabel $(\mathrm{X} 1)$ dan $(\mathrm{X} 2)$ dengan yang lain $(\mathrm{Y})$ dan korelasi ganda dengan analisis Regression Linnear untuk mengetahui hubungan 2 variabel bebas $(\mathrm{X} 1)$ dan $\left(\mathrm{X}_{2}\right)$ secara bersama dengan variabel terikat $(\mathrm{Y})$. 
JURNAL SPORTA SAINTIKA

P-ISSN 2502-5651

E-ISSN 2579-5910

\section{HASIL PENELITIAN}

Setelah dilakukan serangkaian tes menggunakan beberapa instrumen di atas, didapatkan hasil data yang telah di olah sebagai berikut:

\begin{tabular}{|c|c|c|c|}
\hline $\begin{array}{c}\text { Variabel } \\
\text { Independent }\end{array}$ & $\begin{array}{c}\text { Variabel } \\
\text { Dependent }\end{array}$ & $\mathbf{r}$ & Sig. \\
\hline Reaction Time & $\begin{array}{c}\text { Hasil } \\
\text { Smash }\end{array}$ & -0.719 & 0.000 \\
\hline Power Lengan & $\begin{array}{c}\text { Hasil } \\
\text { Smash }\end{array}$ & 0.668 & 0.001 \\
\hline
\end{tabular}

Tabel 1. Hasil Uji Korelasi X1, Y dan X2, Y

\section{A. Korelasi $\mathrm{X} 1$ dengan $\mathrm{Y}$}

Berdasarkan Tabel 1 hasil uji correlate bivariate reaction time dengan kecepatan bola hasil

smash dengan $\mathrm{p}=0.000<0.05$, artinya terdapat hubungan yang signifikan, kemudian nilai $r=-0.719$, arah hubungan negatif bermakna semakin kecil nilai reaction time, semakin besar kecepatan bola hasil smash dengan tingkat hubungan yang kuat.

Hal ini sejalan dengan Koç and Kaya (2006) yang menyatakan bahwa "One of the parameters that enables an athlete to have such performance is reaction time". Selain itu "Pemain tenis meja dituntut untuk merespon dengan cepat karena memungkinkan terjadinya stroke dengan intensitas yang tinggi" Hung, Wu, Lin, Wang, \&Tsai (2007) dalam (lino, Mori, \& Kojima, 2015). Pada olahraga anggar Reaction Time berhubungan erat dengan hasil serangan anggar dengan besar kontribusi 28.5\% (hamidi, 2016)

\section{A. Korelasi $\mathbf{X 2}$ dengan $\mathrm{Y}$}

Hasil uji correlate bivariate power lengan dengan kecepatan bola hasil smash dengan $p=$ 
JURNAL SPORTA SAINTIKA

P-ISSN 2502-5651

E-ISSN 2579-5910

$0.001<0.05$, artinya terdapat hubungan yang signifikan, kemudian nilai $r=0.668$, arah hubungan positif bermakna semakin besar nilai power lengan, maka semakin besar pulsa kecepatan bola hasil smash dengan tingkat hubungan yang kuat.

Hal ini diperkuat oleh Neal (1991) yang menyatakan bahwa Kemampuan untuk menghasilkan kecepatan raket yang tinggi di forehand adalah faktor penting bagi pemain ofensif untuk memenangkan pertandingan. Hal ini karena ayunan dari lengan yang explosive menghasilkan kecepatan bola yang lebih tinggi sebagai akibat paska kontak antara bet dengan bola,dan memberikan peluang lebih sedikit pada lawan untuk melakukan tembakan perlawanan Geske \& Mueller (2010).

\section{B. Korelasi $\mathrm{X} 1, \mathrm{X} 2$ dengan $\mathrm{Y}$}

Untuk mengetahui hubungan reaction time dan power lengan secara bersamasama dengan kecepatan bola hasil smash dianalisis menggunakan uji korelasi ganda.

\begin{tabular}{|c|c|c|c|c|}
\hline $\begin{array}{c}\text { Variabel } \\
\text { Independen }\end{array}$ & $\begin{array}{c}\text { Variabel } \\
\text { Dependen }\end{array}$ & $\mathrm{R}$ & Sig F change & Kesimpulan \\
\hline $\begin{array}{c}\text { Reaction } \\
\text { time dan } \\
\text { Power } \\
\text { lengan }\end{array}$ & $\begin{array}{c}\text { Kecepatan } \\
\text { bola hasil } \\
\text { smash }\end{array}$ & 0.547 & 0.001 & $\begin{array}{c}\text { Terdapat } \\
\text { hubungan } \\
\text { siginifikan }\end{array}$ \\
\hline
\end{tabular}

Tabel 2. Hasil Uji Regression Linnear

Nilai Signifikansi $F$ change $=0.001<0.05$, dengan nilai $r=0.739$ artinya terdapat hubungan yang signifikan antara reaction time dan power lengan secara bersama-sama dengan kecepatan bola hasil smash pada permainan tenis meja. Hal diatas juga sejalan dengan Carrasco et al., (2010) bahwa Tenis meja adalah olahraga asimetris individu, di mana pukulan dengan kecepatan dan power.Tindakan teknis yang terjadi selama pertandingan bersifat unilateral di tingkat trunk dan ekstremitas atas. Dengan demikian sisi dominan pemain beraksi berulang kali dan secara eksklusif. Selain itu dalam olahraga raket kecepatan dan keakuratan bola merupakan 2 parameter teknis yang saling 
JURNAL SPORTA SAINTIKA

P-ISSN 2502-5651

E-ISSN 2579-5910

berkaitan erat mengacu pada kinerja pukulan Girard \& Millet (2009); Rota, Morel,

Saboul, Rogowski \& Hautier (2014).

\section{KESIMPULAN}

disimpulkan bahwa setelah dilakukan analisis terhadap komponen fisik reaction time dan power lengan yang dikorelasikan dengan kecepatan bola hasil smash yaitu (a) Terdapat hubungan yang signifiksan antara reaction time dengan kecepatan bola hasil smash.

(b) terdapat hubungan yang signifikan antara power lengan dengan kecepatan bola hasil smash. (c) terdapat hubungan antara reaction time dan power lengan secara bersama-sama dengan kecepatan bola hasil smash.

\section{SARAN}

Berdasarkan kesimpulan yang telah dikemukakan diatas, maka disarankan agar kedepannya dapat dilakukan penelitian untuk semua komponen kemampuan fisik pada olahraga tenis meja.

\section{DAFTAR PUSTAKA}

Carrasco, L., Pradas, F., Floría, P., Martínez, A., Herrero, R., Antonio, J., \& Jurado, G. (2010). Grip Strength in Young Top-level Table Tennis Players. International Journal of Table Tennis Sciences, 6(6), 64-67.

Djokic, Z. (2014). Basic And Special Physical Preparation Of Top Table Tennis, (January 2003).

Fraenkel, J. R., Wallen, N. E., \& Hyun. H. H. (2013). Biblyografisi Bulunacak., Climate Change 2013 - The Physical Science Basis (Vol. 53).

Geske, Klaus M \& Mueller (2010). Table Tennis Tactics. Singapore: Mayer \& Mayer Sport Girard, O., \& Millet, G. P. (2009). Neuromuscular Fatigue in Racquet Sports. Physical

Medicine and Rehabilitation Clinics of North America, 20(1), 161-173. doi:10.1016/j.pmr.2008.10.008 s://doi.org/10/1017/CBO9781107415324.004

Hamidi, A (2016). Hubungan Reaction Time Dan Coordination Dengan Hasil Serangan Langsung Pada Atlet Ukm Anggar Upi (Doctoral Dissertation, Universitas Pendidikan Indonesia).

Hodges (1996). Tenis Meja Tingkat Pemula. Jakarta : PT. Raja Grafindo Persada.

lino, Y., \& Kojima, T. (2015). Effect of the racket mass and the rate of strokes on kinematics and kinetics in the table tennis topspin backhand. Journal of Sports

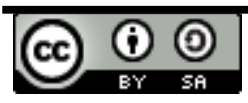

Volume 5, Nomor 1, Maret 2020 sportasaintika.ppj.unp.ac.id 
JURNAL SPORTA SAINTIKA

P-ISSN 2502-5651

E-ISSN 2579-5910

Sciences, 34(8), 721- 729. doi:10.1080/02640414.2015.1069377

Joyce, D., \& Lewindon, D. (n.d.). High-Performance Training for Sports.

Lees, A. (2003). Science and the major racket sports: A review. Journal of Sports Sciences, 21(9), 707-732. https://doi.org/10.1080/0264041031000140275

Mansec, Y. Le, Dorel, S., Hug, F., \& Jubeau, M. (2017). Lower limb muscle activity during table tennis strokes. Sports Biomechanics, 3141(September), 1-11. https://doi.org/10.1080/14763141.2017.1354064

Mackenzie, B. (2004) Ruler Drop Test. from:https://www.brianmac.co.uk/rulerdrop.htm

Neal, R. L.(1991).The mechanics of the forehand loop and drive shots in table tennis. TheAustralianJournalofScienceandMedicineinSport, 23(1),3-11.

Pradas, F., De Teresa, C., Vargas, M.C. (2005). Evaluation of the explosive strength and explosive elastic forces of the legs in high level table tennis players, Sport Science Research, 3, 80-86.

Robert Wood.2015.Softball Throw Test. https://www.topendsports.com

Schmidt, R. A., \& Wrisburg, C. (2004). Motor Learning and Performance. Champaign, IL: Human Kinetics

Sugiyono. (2012). Metode Penelitian. Bandung: CV. Alfabeta Suharismi

Yoshida, K., Hiruta, S., Shimaoka, M., K., F., Ilmoto, Y., \& Yuza, N. (1995). A study on spin control techniques for chop and float services in table tennis. In Y. Hatano (Ed.), Proceedings in FISU/CESU Conference: The 18th Universiade 1995 Sports and Man (pp. 364-365). Fukuoka, Japan: Organizing Committee for the Universiade 1995 